\title{
BUILDING KNOWLEDGE AND SKILLS IN CORPORATE LEARNING AND DEVELOPMENT PROGRAMS: VERIZON CASE STUDY
}

\author{
Raed Sbeit, Verizon, raed.sbeit@verizonwireless.com \\ Ping Wang, Robert Morris University,wangp@rmu.edu
}

\begin{abstract}
Continuous learning and development for knowledge workers is important for modern companies. In today's age of learning and development, the online content, collaboration tools, and social media fuel a training model where employees can share their knowledge and skills freely. Traditional employee training is being revolutionized by flipped classrooms, learning-centric models, and an explosion of content delivered over a variety of new online and mobile platforms. This paper reviews corporate knowledge sharing theories and explores a new training and learning model for corporate learning. The new model highlights the challenges companies must meet to create development programs that really work for their employees. The paper uses the successful case of Verizon to illustrate the new learning and development model and programs and their value to the organization's innovation and productivity.
\end{abstract}

Keywords: Innovation, Information Technology (IT), Knowledge Worker, Knowledge Sharing, Learning and Development, Verizon

\section{INTRODUCTION}

Twenty-first century companies are staffed and propelled by knowledge workers. The term "knowledge worker" was coined by Peter Drucker in a 1959 book titled Landmarks of Tomorrow (Drucker, 1994). Drucker further noted that as a result of the social transformation from the old industrial society to a new knowledge society in the 1990s, the newly emerging knowledge society is characterized by a rising class of knowledge workers who lead and develop a new knowledge-based economy. According to Drucker's description, the rising knowledge workers have access to better-paying jobs that require intellectually challenging qualifications not possessed by industrial workers. To qualify for the jobs of the knowledge economy, knowledge workers must have formal education, the ability to acquire and apply theoretical and analytical knowledge, and the habit of continuous learning of new knowledge. Continuous learning utilizing the ubiquitous information technology and online media is also becoming an inseparable part of the employee professional development for the future workforce. Even though there is a forecast of positive outlook for future employment in most industries, it will be critical to reskill and upskill current workers in order to avoid the possible future scenario of technological developments accompanied by talent shortages, mass unemployment and increasing inequality (World Economic Forum, 2016).

There have been subsequent research and further elaboration on the requirements and qualifications for the knowledge workers for the 21st century. Davenport and Prusak (1998) emphasized that good knowledge workers should possess both technical know-how, such as technical abilities and professional experience, and intuitive skills, such as a sense of cultural, political, and personal aspects of knowledge. Brown (1999) observed that the globalization of work and continuing advances in technology are changing the nature of the work force by directing workers toward the more complex tasks that require thinking, learning, and problem solving. Brown concluded that the main value of knowledge workers to an organization is their ability to gather and analyze information and make decisions that will benefit the organization. Due to the rapid advancements in technology, modern companies often have to update and upgrade the knowledge and skills of their employees in order to maintain their business competiveness (Pretz, 2016).

To help knowledge workers reach their maximum effectiveness and top performance at work, Drucker (1999) identified six major factors related to knowledge workers that determine their productivity in the 21 st century. These factors and demands are: (a) Knowledge workers always ask and know what the task is, (b) knowledge workers have to manage themselves and have autonomy, (c) knowledge workers are responsible for continuing innovation as an 
integral part of their work and task, (d) knowledge workers should keep up learning and knowledge sharing for their knowledge work, (e) knowledge worker productivity is measured primarily not by quantity but by quality of output, and (f) knowledge workers must be treated as valuable assets instead of costs of the organization so that they will enjoy working for the organization. Self-management and autonomy are especially important for knowledge worker productivity. McElroy (2003) proposed the concept of "embryology of knowledge" (p. 105), which means individuals in an organization should have certain extent of freedom to pursue their own ideas and learning agendas and selforganize into knowledge-making groups and communities. According to McElroy, organizations depend heavily on individual interests and passions for inspiration and sources of creative thinking and innovation. Therefore, McElroy suggested that organizational policies should allow workers maximum autonomy, freedom, and self-management in learning and knowledge-sharing. Accordingly, knowledge workers in the 21st century should expect and make the best use of such freedom and autonomy for knowledge work. Drucker (1999) offered important advice on how knowledge workers of the 21 st century should manage themselves to be successful. The advice areas also reflect the desirable characteristics for knowledge workers. According to Drucker, knowledge workers of the 21 st century should focus on and keep improving their strengths to produce the best performance and results. Drucker also warned knowledge workers against bad habits and personality mistakes, such as intellectual arrogance and bad manners, which are detrimental to the effectiveness of knowledge work.

Concurrent with the development of knowledge economy is the rapid development of information technology (IT), which plays an increasingly important role in the knowledge work in the 21 st century. The study by Hlupic, Pouloudi, and Rzevski (2002) confirmed that knowledge workers are increasingly competent in the use of information technology and virtual working environments. Therefore, competency in information technology and emerging communication tools is a required and often assumed qualification for effective knowledge workers of the 21st century. Gurteen (2006) provided a comprehensive list of key attributes describing the habits, skills, values, attitudes, and behaviors of an effective knowledge worker for the 21 st century. These key attributes include strong subject expertise in a specific area and the ability to identify critical knowledge for a certain goal, strong and effective communication and connection skills in networking with other people, and a strong belief in the value of knowledge sharing. According to Gurteen, effective knowledge workers should also demonstrate personal integrity, confidence, and trustworthiness in working with others. In addition, Gurteen pointed out that knowledge workers should be ready to experiment, take calculated risks, and make decisions and take responsibilities.

The next generation of workers are not only knowledge workers but also innovation workers. Innovation is not naturally born a learnable skill (Intrepid Learning Solutions, 2012). The innovation workers not only use knowledge to understand and make decisions and judgement on their work but also keep learning to seek creative solutions to constantly improve their work and products (Herring, 2012). Innovation workers should also have the ability and skills to adapt to changes and stay employable and competitive. Access to education and training opportunities are essential factors for the next generation workers to be both knowledge workers and innovations workers and keep up with the changing world (Brewer, 2013).

Continuous learning by knowledge sharing in a positive learning and development environment is a key success factor to innovation and growth of modern companies. However, there are often challenges and barriers to knowledge sharing and learning in reality. The following sections will review the challenges and solutions to corporate knowledge sharing, explore an effective learning and development model, and present the success story of Verizon in corporate learning and development.

\section{BACKGROUND ON CORPORATE LEARNING AND DEVELOPMENT}

\section{Challenges and Solutions to Corporate Knowledge Sharing}

Corporate knowledge sharing is a critical component of modern knowledge management (KM) because it facilitates new knowledge creation leading to innovations essential to the survival of modern organizations (Gurteen, 1999). However, knowledge sharing is a human issue, and it is people who determine and choose whether or not to share their knowledge willingly (Wheatley, 2001). In reality, there are a number of challenging barriers to employees' willingness to share knowledge within an organization. These barriers include lack of time, not knowing the value of 
knowledge, lack of trust, lack of motivation, and belief in the power of knowledge hoarding. Skyrme (2002) believed that lack of time is probably the most common reason given by people in organizations for not sharing their knowledge. According to Skyrme, it is difficult for employees in modern organizations to find time for knowledge sharing because they are often multitasking and pressured by productivity demands and deadlines. To solve this problem, organizations should establish knowledge sharing as a top priority and give employees adequate time and freedom for knowledge sharing and exchange. McElroy (2003) suggested that organizational policies should allow individuals certain extent of freedom to pursue their own ideas and learning agendas and to self-organize into knowledge groups and communities. As an example, Google successfully implemented and benefited from its policy of allowing and paying staff to pursue their own ideas freely during $20 \%$ of their work time and encouraging individuals and teams to share details of their projects within the organization (Machlis, 2009).

Another reason why employees do not share their knowledge is that they have not realized how useful and valuable their particular knowledge is to others (Skyrme, 2002). Some individuals, especially those in lower ranks of a team, often underestimate their experience and intellect and feel having nothing valuable to contribute to the team (Goman, 2002). To help overcome this barrier, Goman suggested that managers and team leaders, while encouraging group collaboration and sharing of mistakes and lessons learned, should openly recognize and emphasize individual strengths to make everyone feel valued and respected. Goman also indicated that team leaders should encourage and respect everyone's contribution and help all members recognize what each of them can bring to the team. Lack of trust is a major barrier to knowledge sharing within an organization. An organizational culture based on trust is essential to a positive environment for organizational learning and knowledge-sharing. Naturally, people will not share their experience and know-how with others they do not know well or trust. Davenport and Prusak (1998) stated that knowledge initiatives will fail without visible, reciprocal, and ubiquitous trust in an organization. To build an organizational culture of collaboration based on trust, Goman (2002) suggested that giving people enough time to develop trusting relationships by learning and adapting to each other's strengths and weaknesses. DeSouza (2003) also proposed a humanistic approach of developing trusting relationships among members of an organization for sharing their know-how through informal and entertaining activities, interactions, and dialogues. Nenonen, Jensen, and Lindahl (2014) proposed the knowledge mapping approach to identify the knowledge gaps and needs to improve knowledge sharing and knowledge flow.

Lack of motivation is another factor that discourages knowledge sharing. The motivation for people to share knowledge is critical to the success of KM implementations (Davenport, De Long, \& Beers, 1998). Davenport et al. emphasized that effective motivational incentives and practices should not be trivial but long-term and tied in with the performance evaluation and compensation structure. To participate in knowledge sharing willingly, employees should expect rewarding and positive consequences without fear for any negative consequences. Goman (2002) suggested that employees should never be ridiculed, criticized, threatened, or punished for their insights and opinions. Instead, as Garfield (2006) proposed, organizations should implement rewards and recognition programs for those who share their knowledge. Knowledge hoarding is the opposite of knowledge sharing and certainly an obstacle to any knowledge sharing initiative. Some knowledge owners keep themselves out of the knowledge sharing process because they believe in the power of knowledge and the greater benefit of hoarding it than sharing it in a competitive environment (Davenport \& Prusak, 1998). Davenport and Prusak considered knowledge hoarding as a realistic challenge for KM initiatives and suggested rewarding knowledge sharing more than knowledge hoarding. In addition to rewarding and motivating employees for knowledge sharing, organizations should educate employees on the transparency and collaboration requirements for knowledge work. Tapscott (2003) concluded that all three categories of modern knowledge work (i.e. procedural, heuristic, and executive), require internal transparency and visibility of processes and operations, which means that employees have to share unprecedented amounts of knowledge to work effectively. The study by Oye, Salleh, and Moorminshah (2011) found that the need and pace for innovation and knowledge sharing may vary from industry to industry and concluded that "technology plays a critical role in creating, storing and distributing explicit knowledge in an accessible and expeditious manner" (p.81). A good example is the Teaching Factory paradigm using distance-learning knowledge delivery technology proposed by Chryssolouris, Mavrikios, and Mourtzis (2013). 


\section{Positive Attributes for Corporate Knowledge Management}

Effective corporate training and knowledge sharing depend on a positive and constructive knowledge management environment. Davenport, De Long, and Beers (1998) and Davenport and Prusak (1998) identified eight common attributes that contribute to a successful knowledge management (KM) implementation based on their studies of successful KM projects. There are eight contributing factors to KM success: A knowledge-oriented culture, technical and organizational infrastructure, senior management support, link to economic performance or industry value, clear vision and language, nontrivial motivational practices, standard and flexible knowledge structure, and multiple channels for knowledge transfer.

A knowledge-oriented culture is critical to the success of a KM implementation (Davenport \& Prusak, 1998). Important components of a knowledge-oriented culture for an organization includes a positive orientation to knowledge creation and use, absence of resentment or fear of job loss in knowledge sharing, and a fit between the KM initiative and the organizational culture (Davenport, De Long, \& Beers, 1998). McElroy (2003) also advocates a positive organizational learning culture that gives employees freedom to pursue their learning agendas for knowledge creation and innovation.

Technical and organizational infrastructure is a contributing factor to the success of a KM implementation. Technical infrastructure includes knowledge-oriented tools and a uniform set of technologies, such as computer systems and networks, which facilitate information and knowledge communication (Davenport, De Long, \& Beers, 1998). It is also important to the success of the KM initiative that adopted technologies match the business category and knowledge sharing needs of the organization (Kankanhalli, Tanudidjaja, Sutanto, \& Tan, 2003). Organizational infrastructure, according to Davenport et al., refers to the established organizational structures, roles, and knowledge support staff members and their skills that can benefit the KM implementation.

Support from senior management is beneficial to the success of a KM implementation. This type of support is especially critical if the KM initiative is intended to transform or reengineer the organization in a certain way (Davenport \& Prusak, 1998). The main components of senior management support include openly emphasizing the importance of the success of the KM initiative to the organization, providing funding and other resources for infrastructure, and clarifying the types of knowledge most important to the organization (Davenport, De Long, \& Beers, 1998).

KM initiatives can be expensive and need understanding and support of the entire organization. One way to gain support from the organization is to link the KM implementation to economic performance, industry value, or competitive advantage (Davenport, De Long, \& Beers, 1998). Financial returns and improvements of process cycle time and customer satisfaction related to the KM initiative, according to Davenport et al., are all indicators of accomplishments, which will in turn win increased support for the KM initiative from the organization.

Clear vision and language is especially important to the success of a KM implementation. Since some key KM-related terms and concepts, such as knowledge, information, data, and organizational learning, are subject to varied use and interpretation, it is important to provide clear definitions of these terms and concepts and KM objectives so as to gain wide understanding and acceptance of the KM initiative (Davenport, De Long, \& Beers, 1998). For example, equating knowledge with information is a common conceptual confusion that should be corrected because it is a narrow view that is blind to many important social and human elements of KM, such as trust, culture, social networks, creativity and innovation, and human competencies in learning and knowledge sharing (Holsapple, 2005).

The motivation for people to create, share, and use knowledge is an intangible but critical factor to the success of any KM implementation (Davenport, De Long, \& Beers, 1998). Davenport et al. emphasized that effective motivational incentives and practices should not be trivial but long-term and tied in with the performance evaluation and compensation structure. DeSouza (2003) recognized the challenge for organizations to motivate employees to share valuable tacit knowledge, and he proposed the humanistic approach to establish informal and entertaining interactions and dialogues among people for them to share and exchange their know-how with pleasure. Positive motivations will also help to remove various barriers to knowledge sharing in the corporate environment. 
It is necessary to have a standard and flexible knowledge structure for many KM implementations to be successful. Without standard categories and key terms in a knowledge repository system, it will be difficult for people to search and extract knowledge from the system (Davenport, De Long, \& Beers, 1998). On the other hand, according to Davenport et al., the knowledge structure should be flexible and open to continuous updates since knowledge itself is constantly changing. In addition, Jerald (2009) emphasized that knowledge structure and workforce competencies should also emphasize practical knowledge application skills as well as creativity, critical thinking, problem solving, and communication skills in the fast changing workplace.

Finally, multiple channels for knowledge transfer also contribute to the successful KM implementation. Davenport and Prusak (2008) recognized that face-to-face meetings with knowledge contributors are more preferable for certain occasions where trust establishment is of prime importance, whereas use of information technology (IT) tools and networks can transcend time and distance if efficiency is desired for knowledge communication and sharing. In addition, the effectiveness of different channels depends on different knowledge needs. For example, electronic knowledge repositories are most effective for codification and storage of explicit and structured knowledge, whereas direct personal communication or videoconferencing is best for transfer and sharing of personalized tacit knowledge (Kankanhalli, Tanudidjaja, Sutanto, \& Tan, 2003).

\section{METHODOLOGY}

This paper compares the traditional and modern corporate learning models, identifies positive attributes for an effective corporate learning knowledge sharing model, and uses Verizon as a case study to demonstrate the modern model for corporate learning and development. Historically, corporate managers passed on knowledge, skills, and insights through coaching and mentoring. But in our modern global, complex, and competitive world, the role of the manager has eroded. Managers are now overburdened with responsibilities. They can barely handle what they're directly measured on, let alone offer coaching and mentoring. Organizations need to support and incentivize managers to perform this work. IT enhances leisure time and enriches culture by expanding the distribution of information, relieves pressures on urban areas by enabling individuals to work from home or remote-site offices (Garcia, 2009), changes the way we work, and the way we work with one another. Telecommuting arrangements can help improve employee productivity (Shockley, 2014). It used to be that one's learning was good for years, but now knowledge and skills can become quickly obsolete (Ferrazzi, 2015). The need for continuous learning and development demands an effective corporate knowledge management and learning and development model.

\section{Verizon Case Study}

Verizon (VZ) is a global leader in providing communications and technology solution for our customers to play, work and live. Verizon's mission is to deliver the promise of the connected World. In 2015, Verizon invested more than $\$ 11$ billion to meet today's surging demand for wireless data and video, but also to get Verizon network ready for 5G wireless technology. According to RootMetrics $\mathbb{C}$, the largest independent third-party tester of wireless network performance, Verizon ranks number one in speed, data, reliability and overall network performance in the U.S. To keep employee knowledge and skills up to date to maintain the corporate competitiveness, Verizon has been implementing a learning and development model for the past 10 years that incorporates an encouraging environment for knowledge sharing and positive attributes for knowledge management, professional training, and innovation. As reported by Freifeld (2012), Verizon's learning and development (L\&D) program model has the following attributes:

Verizon's learning and development program model aims to create a knowledge-oriented culture throughout the organization. A knowledge-oriented culture is critical to the success of a KM implementation (Davenport \& Prusak, 1998). Verizon created customized training programs for various levels of employees, from the executive leaders to the new hires from colleges and universities (Freifeld, 2012). The training programs are designed maximize knowledge transfer and sharing opportunities for everyone to reach their potential. Strategically, Verizon prioritizes employee learning and development as a critical part of the corporate plan for new products and services and all employees are encouraged to grow professionally (Salopek, 2014). 
Verizon's learning and development program model includes important and technical and organizational infrastructure. Technical infrastructure includes knowledge-oriented tools and a uniform set of technologies, such as computer systems and networks, which facilitate information and knowledge communication (Davenport, De Long, $\&$ Beers, 1998). For example, Verizon designed and successfully implemented the Verizon Learning Systems which blended online e-learning with classroom training, mentoring programs, and access to the company's internal Knowledge Management system called the "knowledge bank" for new hire sales training. The online Web-based training portion provides initial training about products and services with follow-up mentoring assigned to new salespeople to guide them along their curriculum plan with access to subject matter experts (Hall \& LeCavalier, 2000). The e-learning technology infrastructure plays a key role in providing basic information and reinforcing skills in Verizon's Integrated Learning Solution.

Verizon's learning and development program model enjoys consistent support from senior management. Learning initiatives and activities can be expensive and need understanding and support of the entire organization. One way to gain support from the organization is to link the KM implementation to economic performance, industry value, or competitive advantage (Davenport, De Long, \& Beers, 1998). Since all training activities are closely tied to Verizon's strategic business goals and values, they have consistent support from the top management and the entire organization. Members of executives participate in executive training. Senior leaders and board directors even lead some of the training sessions (Freifeld, 2012).

Verizon's learning and development program model has a clear vision. The training and learning activities are linked to three business goals: 1) To build a business and workforce as good as its networks; 2) To lead in shareholder value creation; 3) To be recognized as an iconic technology company. Specific objectives of training focus on innovation with technology. For example, Verizon has been align their training with delivering innovative technology to their customers, including innovative technology training on 4G LTE and mobile operating system updates and upgrades (Freifeld, 2012).

Finally, Verizon's learning and development program model has strong motivation for employee participation. Davenport et al. (1998) emphasized that effective motivational incentives and practices should not be trivial but longterm and tied in with the performance evaluation and compensation structure. DeSouza (2003) proposed the humanistic approach to establish informal and entertaining interactions and dialogues among people for them to share and exchange their know-how with pleasure. Verizon's training and learning activities are tied to performance evaluation. For example, Verizon Wireless (VZW), uses a customer service New Hire Training (NHT) Scorecard to monitor new hire performance at 30,60, 90, and 120 days post-training. In addition, Verizon provides leadership path opportunities and supportive training opportunities and awards and recognitions to encourage traditionally underrepresented populations such as women to enter leadership positions (Freifeld, 2012; PRISM International, 2013). These positive motivations will also help to overcome various challenges and barriers to knowledge sharing in the corporate environment. In addition, all employees have professional development plans with technologyassisted knowledge sharing, including access to social networking tools, internal online forums and a video-sharing site that support learning (Salopek, 2014).

\section{FINDINGS AND DISCUSSIONS}

The following results reported by Freifeld (2012) reflect on the effectiveness and success of Verizon's learning and development program model:

- The total number of Verizon employees and independent contractors or franchisees trained overall annually is: 286,411 .

- The total number of employees and independent contractors/franchisees trained annually via instructor-led classroom sessions is 179,140 .

- The total number of employees and independent contractors/ franchisees trained annually via online, selfpaced study is 286,411 , which indicates that increased use of online e-learning technology system even among those taking instructor-led sessions.

- The number of courses offered as instructor-led classroom sessions is 990 . 
- The number of courses offered as instructor-led virtual classroom sessions is 337 .

- The number of courses offered as online-self-paced modules is 11,440 , which is evidence of effective use of technology in learning and development to facilitate working professionals.

- The annual revenues generated by the knowledge workforce is: $\$ 106.6$ billion.

- The average length of employee service is 12 years, which is pretty high in corporate environment.

- The percentage of job openings filled by internal candidates is 51 percent, which reflects on the effectiveness of internal employee professional development.

As a result of the outstanding performance, Verizon was ranked Number One on the Training Top 125 in 2012 and appeared five times in the Top 10 during the previous six years (Freifeld, 2012). Looking ahead to 2022, Verizon plans to increase mobile and online training to develop a workforce that is well-versed in using personalized mobile online performance support.

In addition to the quantitative performance metrics above, Verizon has used qualitative metrics through self-evaluation as well as consultation with the external KnowledgeAdvisors, who assessed the maturity of company's learning effectiveness and developed a three-year roadmap for steady progress (Salopek, 2014). In spite of the previous success, Verizon continues to provide formal and informal training opportunities on technical and soft skills for all employees by using a variety of technology-based delivery formats, such as massive open online courses (MOOCs), simulations, instructional videos and e-books (Pretz, 2016).

\section{SUMMARY}

Twenty-first century knowledge workers need frequent learning and professional development to keep up their knowledge and skills in order drive corporate innovation and competitiveness. However, there are various challenges and barriers to knowledge sharing and learning in a corporate environment and effective learning, and development models and programs with positive attributes and motivation are needed to implement effective corporate knowledge management and successful learning and development. Examples of positive learning environment attributes include a knowledge-oriented culture, technical and organizational infrastructure, senior management support, link to economic performance or industry value, clear vision and language, nontrivial motivational practices, and standard and flexible knowledge structure, and multiple channels for knowledge transfer.

This paper reviews relevant knowledge management and knowledge sharing theories for modern knowledge workers in the corporate environment. The paper identifies positive attributes for effective corporate knowledge sharing and professional development and presents the case study of Verizon's successful learning and development program as a case example. Verizon's training model program has a clear vision linked to strategic business goals, enjoys consistent support from corporate leadership, and provides incentives and motivational opportunities for employees to participate and succeed.

It is well known that knowledge is power, which leads to innovations, competitiveness, and better performance for modern corporations. This study is preliminary study on corporate knowledge development bases on a case study of a telecommunications company. Future studies may focus on a specific area of corporate training and learning, such as in mobile technical support, with measures of the performance progress over a certain period of time. Another promising area relevant to this study is to focus on the effect of online learning and training on employee professional development and performance. It would be ideal to have a control group, if possible, to compare the performance differences between the groups with training and the group without training. Additionally, further research in this area may also expand to other and different industry and business environments to increase the scalability of the study and compare the effectiveness of various corporate learning and development models. 


\section{REFERENCES}

Brewer, L. (2013). Enhancing youth employability: What? Why? and How? Guide to core work skills. International Labor Organization. Retrieved from http://www.ilo.org/wcmsp5/groups/public/---ed_emp/--ifp_skills/documents/publication/wcms_213452.pdf

Brown, B. L. (1999). Knowledge workers. Trends and Issues Alert, no. 4.

Capgemini Consulting and MIT Center of Business Digital Research, Digital Transformation: A Roadmap of Billion dollar Organizations, 2011

Chryssolouris, G., Mavrikios, D., \& Mourtzis, D. (2013). Manufacturing systems: Skills \& competencies for the future. Procedia CIRP, 7(2013), $17-24$.

Davenport, T. H., De Long, D., \& Beers, M. (1998). Successful knowledge management. Sloan Management Review, 39(2), 43-57.

Davenport, T. H., \& Prusak, L. (1998). Working knowledge: How organizations manage what they know. Cambridge, MA: Harvard Business School Press.

Desouza, K. C. (2003, June). Facilitating tacit knowledge exchange. Communications of the ACM, 46(6), 85-89.

Drucker, P. F. (1994, November). The age of social transformation. The Atlantic Monthly, 274(5), 53-80.

Drucker, P. F. (1999). Management challenges of the 21st century. New York, NY: Harper Business.

Ferrazai, K. (2015, July 31). 7 Ways to improve employee development programs. Harvard Business Review. Retrieved from https://hbr.org/2015/07/7-ways-to-improve-employee-development-programs

Freifeld, L. (2012). Verizon's new number is 1. Training: The source for professional development. Retrieved from https://trainingmag.com/content/verizon\%E2\%80\%99s-new-number-1

Garfield, S. (2006). 10 reasons why people don't share their knowledge. Knowledge Management Review. Retrieved from http://stangarfield.googlepages.com/10reasonswhypeopledontsharetheirknow.pdf

Goman, C. K. (2002). Five reasons people don't tell what they know. Knowledge Management. Retrieved from http://www.destinationkm.com/articles/default.asp?ArticleID=960

Gurteen, D. (1999, February). Creating a knowledge sharing culture. Knowledge Management Magazine, 2(5), 1-4.

Gurteen, D. (2006). What makes an effective knowledge worker? Retrieved from http://www.gurteen.com/gurteen/gurteen.nsf/id/kw-habits

Hall, B., \& LeCavalier, J. (2000). E-learning across the enterprise: The benchmarking study of best practices. Retrieved from http://www.jacqueslecavalier.com/samples/Blended\%20learning\%20and\%20Basic\%20Blue\%20excerpt.pd $\mathrm{f}$

Herring, S. (2012). Rethinking the knowledge worker for the 21st century. In The innovation worker: Rethinking the knowledge worker for the 21st century (pp. 1-2).

Retrieved from http://intrepidlearning.com/downloads/ebooks/eBook-Intrepid-InnovationWorker.pdf

Hlupic, V., Pouloudi, A., \& Rzevski, G. (2002). Toward an integrated approach to knowledge; management: 'Hard', 'soft', and 'abstract' issues. Knowledge and Process Management, 9(2), 90-102. 
Holsapple, C. W. (2005). The inseparability of modern knowledge management and computer-based technology. Journal of Knowledge Management, 9(1), 42-52.

Intrepid Learning Solutions. (2012). The innovation worker: Rethinking the knowledge worker for the 21st century. Retrieved from http://intrepidlearning.com/downloads/ebooks/eBook-Intrepid-InnovationWorker.pdf

Jerald, C. D. (2009). Defining a 21 st century education. Retrieved from http://www.centerforpubliceducation.org/Learn-About/21st-Century/Defining-a-21st-Century-EducationFull-Report-PDF.pdf

Kankanhalli, A., Tanudidjaja, F., Sutanto, J., \& Tan, B. C. Y. (2003, September). The role of IT in successful knowledge management initiatives. Communications of the ACM, 46(9), 69-73.

Machlis, S. (2009, February 2). Innovation and the 20\% solution. Computerworld, 43(5), 21.

McElroy, M. W. (2003). The new knowledge management: Complexity, learning, and sustainable innovation. Boston: Butterworth-Heinemann.

Nenonen, S., Jensen, P. A., \& Lindahl, G. (2014). Knowledge map of facilities management. In K. Alexander (Ed.), Promoting Innovation in FM. 13th EuroFM Research Symposium (EFMC 2014). 1-12.

Oye, N. D., Salleh, M., \& Moorminshah, A. (2011). Knowledge sharing in workplace: Motivators and demotivators. International Journal of Managing Information Technology (IJMIT), 3(4), 71-84.

Pretz, K. (2016, September 21). Innovative corporate training programs keep employees' skills updated: Verizon and VMware are using customized MOOCs, videos, and e-books. Retrieved from $\mathrm{http}$ //theinstitute.ieee.org/career-and-education/education/innovative-corporate-training-programs-keepemployees-skills-updated

PRISM International. (2013). Case study: Verizon Wireless \& developing women leaders. Retrieved from https://www.prismdiversity.com/downloads/VZW_WomenLeaders.pdf

Salopek, J. J. (2014). Tying learning to strategy at Verizon. Retrieved from https://www.td.org/Publications/Magazines/TD/TD-Archive/2014/10/BEST-Verizon

Shockley, K. (2014). Telecommuting. Retrieved from http://www.siop.org/whitepapers/scientificaffairs/telecommuting/telecommuting.pdf

Skyrme, D. J. (2002, August). The 3Cs of knowledge sharing: Culture, co-opetition, and commitment. Retrieved from http://www.skyrme.com/updates/u64_fl.htm

Tapscott, D. (2003, September 1). Sharing leads to abundance. Intelligent Enterprise, 6(14), 12, 44.

Wheatley, M. J. (2001, April-June). The real work of knowledge management. IHRIM Journal, 5(2), 29-33.

World Economic Forum. (2016, January). The future of jobs: Employment, skills and workforce strategy for the fourth industrial revolution. Retrieved from http://www3.weforum.org/docs/WEF_Future_of_Jobs.pdf 